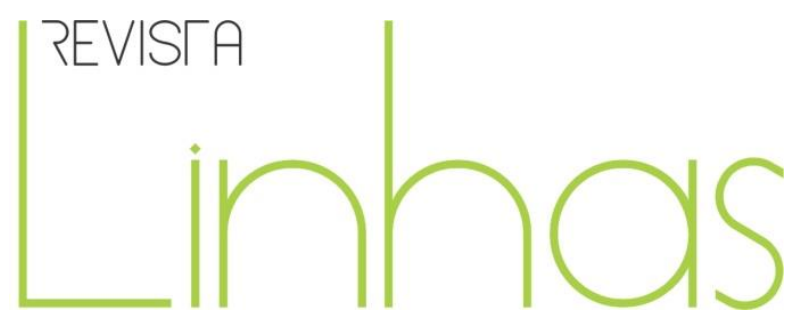

\title{
Bio:grafias e produção de diferenças no cotidiano escolar: uma reflexão sobre sexualidades a partir do cinema
}

\begin{abstract}
Resumo
A presente pesquisa volta-se para o debate do uso do cinema e da produção de bio:grafias (REIGOTA; PRADO, 2008) no cotidiano escolar como possibilidade de tornar mais singulares os olhares dos/as alunos/as do ensino médio, da rede estadual paulista, em relação às questões das sexualidades. Assim, como ampliar os saberes do senso comum - geralmente carregado de preconceitos, dialogando, para tal, com as perspectivas da educação menor (GALLO, 2003), por apostar em práticas pedagógicas cotidianas como potencializadoras de produzir diferenças e buscar construir coletivamente, nas "trincheiras do desejo", cavadas no chão da sala de aula: acontecimentos. Pretende-se, dessa forma, evidenciar as experiências transformadoras e criativas do cotidiano escolar como possibilidade para a formação de alunos/as e professores/as que se criam e recriam, transformam e se transformam, sempre nas singularidades, em diferentes momentos e no jogo da diferença, vivenciando sexualidades fluídas e, colocando por terra as dicotomias criadas histórica, social e culturalmente pelo Ocidente e mantidas pelos mecanismos disciplinares (FOUCAULT, 2007a) da sociedade em que vivem.
\end{abstract}

Palavras-chave: Bio:grafias; Cinema na educação; Educação menor; Sexualidades; Cotidiano escolar.

\author{
Eder Rodrigues Proença \\ Doutorando em Educação pela \\ Universidade de Sorocaba - \\ UNISO - Brasil \\ eder.proenca1@gmail.com
}

\footnotetext{
Para citar este artigo:

PROENÇA, Eder Rodrigues. Bio:grafias e produção de diferenças no cotidiano escolar: uma reflexão sobre sexualidades a partir do cinema. Revista Linhas. Florianópolis, v. 16, n. 32, p. 200 - 220, set./dez. 2015.
} 


\title{
Bio:narratives and production of the differences in school everyday: a reflection on sexualities from the cinema
}

\begin{abstract}
This current research holds a dialogue with the use of the cinema and the production of bio: narratives(REIGOTA; PRADO, 2008) in school everyday as a possibility to make it more unique the looks of the male and female students of high school, from the state schools of the State of São Paulo, regarding the issues of sexualities, as well as to enhance the knowledge of common sense - usually reinforced with prejudice, holding a dialogue with the perspectives of the minor education (GALLO, 2003), staking on everyday pedagogical practices as driving forces for producing differences and for building collectively, the "trenches of desire", which were drawn out of the classroom floor: events. Therefore, it has been aimed to highlight the transforming and creative experiences of school everyday as a possibility to the formation of male and female students and male and female teachers who create and recreate themselves, who transform and transform themselves, always in their singularities, and in different moments and in the game of the difference, experiencing fluid sexualities and debunking the dichotomies that were historically and social and culturally created by the Western and that were maintained by the disciplinary mechanisms (FOUCAULT, 2007a) of the society in which they live.
\end{abstract}

Keywords: Bio:narratives; Cinema in school; Minor education; Sexualities; School everyday. 
[...] parafraseando Michel Foucault -, queremos contribuir para a anulação das muitas formas de fascismo, sejam aquelas formas imensas que se abatem sobre nós e nos sufocam, sejam aquelas formas minúsculas e sutis que nos assombram e nos mantêm presos e submissos a nós mesmos. (RAGO; VEIGANETO, 2009, p. 11)

Os discursos sobre sexualidade produzidos na/pela escola, são carregados, na maioria dos casos, por representações preconceituosas, pautadas nas pedagogias da sexualidade, construídas a partir de um modelo tido como "normal" - o homem branco e heterossexual (LOURO, 2004). A partir de tal modelo, todos/as aqueles/as que se apresentam como distintos, passam a ser relegados e excluídos socialmente ou são incluídos, sempre a partir de um "desde que” observem condições pré-estabelecidas, não extrapolando normas, códigos e fronteiras, como afirma Louro (2008, p. 21) “hoje, tal como antes, a sexualidade permanece como alvo privilegiado da vigilância e do controle das sociedades. Ampliam-se e diversificam-se suas formas de regulação, multiplicam-se as instâncias e as instituições que se autorizam a ditar-lhe normas".

Por outro lado, existem outros discursos, que produzidos principalmente por aqueles/as aos quais chamo de corpos estranhos - jovens e adolescentes, professores e professoras - que subvertem a lógica heteronormativa, apontam linhas de fuga e a emancipação das minorias sexuais, resgatando para as/os mesmas/os o papel de sujeitos cidadãos (PROENÇA, 2009).

Corpo é entendido não apenas como constituição física dos indivíduos, mas numa perspectiva que dialoga com Louro (2004), dimensionado ao gênero e a sexualidade, ou seja, como produção inscrita discursivamente em cada indivíduo. Corpo estranho seria, assim, todo/a e qualquer indivíduo que resiste e enfrenta as normas pré-estabelecidas socialmente, dando vez e voz àqueles que se encontram às margens, fazendo extrapolar o sentido de cidadania. 
O trabalho para transformar os primeiros discursos em outros, pautados na valorização da diferença e da diversidade sexual tem sido feito a duras penas e, aos poucos, vem sendo ampliados, ao se mostrarem fundamentais em diversos espaços sociais como a escola.

Uma experiência singular vivenciada dentro da escola aconteceu a partir do filme Transamérica (2005), com uma turma de ensino médio, da rede estadual paulista, na cidade de Sorocaba. Consistiu em organizar a sessão de cinema com o filme, sugerido por um dos alunos, quando trabalhava as questões das minorias, o preconceito, o crescente nacionalismo e a xenofobia, principalmente em países europeus, mas não só neles, que estão numa crescente na contemporaneidade.

Apesar de num primeiro momento a atividade apenas ter apontado algumas representações sociais, vivências e experimentadas pelos/as alunos/as, marcadas pelo tipo de formação que receberam em casa, na igreja que participam e do senso comum, difundido no cotidiano, por inúmeros dispositivos disciplinares (LOURO, 1999); após a sessão do filme e as reflexões propostas, perceberam-se alguns avanços: a desconstrução das formas de pensamento, de classificação e de regulação dos indivíduos; a compreensão dos sujeitos e corpos como compostos por múltiplas identidades e; inclusive, a percepção de que as sexualidades podem ser cambiantes e ou fluídas, despertando a valorização da alteridade nas/das diferenças.

Num investimento que Gallo (2003) chama de educação menor, pode-se pinçar algumas pistas que contribuem com a possibilidade de pensar a si e aos outros como construtos históricos, pensar a lógica social formatadora de sujeitos e perceber linhas de fuga, que muitos corpos estranhos estão empreendendo para ampliar o sentido de cidadania, na busca de uma formação mais ética, democrática e reflexiva, como quando nos deparamos, por exemplo, com uma travesti sorocabana, que através de sua presença e atitude no cotidiano escolar, amplia o potencial de sua trajetória ao dialogar com o pensamento de Paulo Freire (2000), buscando na educação, a autoconstrução enquanto sujeito de sua própria história e da história coletiva.

Assim, a presente pesquisa tem por objetivo maior investigar como ações do cotidiano escolar (educação menor), que não estão dentro dos currículos oficiais, podem fazer extrapolar as percepções dos/as alunos/as em relação às temáticas caras da 
contemporaneidade, em específico àquelas ligadas às sexualidades, como possibilidade de criar o novo e construir um futuro "para além de qualquer política educacional" (GALLO, 2003, p 78).

\section{Bio:grafias como procedimento metodológico de investigação}

A pesquisa é estruturada a partir da etnografia, assim, não há pretensão de analisar as produções dos/as alunos/as, validando-as como verdades ou não verdades, mas sim, dar voz a esses sujeitos, numa perspectiva de captar suas reflexões no/do/com cotidiano escolar, onde borbulha uma infinidade de temas relevantes para a contemporaneidade, tornando latentes, as questões sobre sexualidades e seus desdobramentos, exploradas neste trabalho.

O intuito é a aproximação do que nos sugere Amorim (2005, p. 115),

[...] pensar em formas de olhar para e produzir tais imagens como recursos de construção de nossas experiências cotidianas e de nosso imaginário e não uma expressão que possa ser submetida à análise e interpretação, assumida como possível e verdadeira nas apresentações do cotidiano.

É possível, então, desviar de sua compreensão como documentos, como provas, como artifícios de trazer sujeitos reais, situações concretas e aspectos de contexto para a escrita que quer se impregnar cotidiano.

Para tanto, utiliza-se como base as bio:grafias, proposta de Reigota e Prado (2008) - bio seria a relação existencial, profissional e política do sujeito e, grafia a narrativa da presença do sujeito no mundo - como exercícios singulares e que se tornaram pertinentes, pedagógica e politicamente, suscitando novos e múltiplos conhecimentos e a efetivação de uma cidadania ampliada, assim, podem possibilitar um trabalho de aprofundamento teórico e metodológico inovador, para (re)significar práticas pedagógicas no/do/com cotidiano escolar.

Aceitando o convite que Guattari (1997) nos faz em As três ecologias - que seria pensar as questões contemporâneas sobre um novo olhar que articule e valorize o campo da ética-política e da ética-estética, proporcionando singularidades que fogem dos 
padrões impositivos do desenvolvimento técnico-científico - penso que as bio:grafias, como uma cartografia subjetiva dos personagens do cotidiano escolar, é a experiência de romper com paradigmas ossificados pela sociedade capitalista, em suas diferentes instâncias, possibilitando vivências, cada vez mais amplas, de novas práticas, que reinventam formas de experimentação de ser-em-grupo, a partir de uma inspiração éticoestética. Um viés de construção dos “novos contratos de cidadania” (GUATTARI, 1997, p, 35) e a maneira como assumir a própria psique,

Novas práticas sociais, novas práticas estéticas, novas práticas de si na relação com o outro, com o estrangeiro, com o estranho: todo um programa parecerá bem distante das urgências do momento! E, no entanto, é exatamente na articulação: da subjetividade em estado nascente, do socius em estado mutante, do meio ambiente no ponto em que pode ser reinventado, que estará em jogo a saída das crises maiores de nossas épocas. (GUATTARI, 1997, p. 55)

O uso das bio:grafias no cotidiano escolar - produções singulares das trajetórias pessoais dos sujeitos -, oferece para a educação, um salto na reflexão do tipo de escola que devemos investir na contemporaneidade, pois, eis que ao ressaltar as vivências e particularidades, suas desconstruções/construções ao se depararem com temas importantes de nosso cotidiano, apontam a necessidade de ampliação do sentido de cidadania e de efetivação do papel de sujeitos de si e da história coletiva.

Reigota e Prado (2008, p.125), escrevem que o objetivo do uso das bio:grafias, em seu trabalho é,

[...] trazer para o espaço público, com critérios de validade e de pertinência pedagógica, textos escritos por anônimos, nos quais o que se pretende não é observar como eles narram, mas sim como se vêem e se situam no contexto dos fatos e o interesse que essas narrativas na constituição do currículo (em processo) da formação profissional e de identidade profissional, cultural e política.

As bio:grafias se constituem, portanto, como exercício de registrar ficcionalmente discursos, imagens reais ou não de si mesmo e da sociedade. Elas não são, segundo os autores, biografias, ou seja, a trajetória de vida de um personagem real, 
escrito por outra pessoa, a partir de suas interpretações; nem ao menos, são autobiografias que apresentam detalhes da vida de seus autores.

O uso das bio:grafias pode ser uma possibilidade metodológica pois,

[...] seu conteúdo pautado nas trajetórias pessoais relacionadas prioritariamente com a temática ambiental, nos seus aspectos culturais, políticos, sociais, econômicos e ecológicos, e por serem resultantes de processos pedagógicos [...] expressam representações sociais [...] e conhecimentos obtidos da observação e vivências cotidianas.

Dessa forma, favorecem a visibilidade de "zonas desconhecidas" e são um convite para adentrarmos à intimidade e privacidade com cumplicidade e abertura ao diálogo entre autor/a e leitor/a. Para isso, as bio:grafias precisam refletir a veracidade dos fatos e sentimentos narrados.

Por último, as bio:grafias permitem a presença de "múltiplas vozes" no espaço público sobre temáticas, conhecimentos, vivências e aspectos do cotidiano de locais específicos através dos relatos de seus cidadãos e cidadãs [...] (REIGOTA; PRADO, 2008, p. 129)

$\mathrm{Na}$ educação, as bio:grafias podem revelar muito, pois de acordo com Pontuschka (2000, p. 152), "a linguagem do aluno, assim como a das pessoas em geral, está impregnada de significados, de conhecimentos, de emoção, de afeto, sendo que alguns são explícitos, enquanto outros precisam ser desvelados por meio de acurada reflexão", ou seja, os sujeitos do cotidiano escolar e/ou fora dele, suas linguagens, conhecimentos e experiência de vida, são rizomáticos (DELEUZE, GUATTARI, 1995).

Gallo (2002), afirma ser um novo paradigma para a educação, que não pode se restringir à transmissão dos conhecimentos oficializados pelos parâmetros e propostas curriculares, mas, deve se ater ao rico cotidiano, no qual um emaranhado de questões surgem em emergências e acontecimentos que não será uma ou outra disciplina a tensioná-los, mas o conjunto delas, interdisciplinarmente, resgatando e respeitando os conhecimentos e culturas de cada grupo, em cada espaço.

Dessa forma, recorrendo às discussões teóricas contemporâneas sobre currículo e práticas pedagógicas no/do/com cotidianos escolares, pretendo trazer para o debate e reflexão como o investimento na educação menor pode provocar a formação através de experiências singulares, transformadoras e criativas, de sujeitos que se inventam, em 
diferentes momentos, resistindo a padrões e regras impostos, viabilizando a produção de diferenças, como aponta Gallo (2007, p. 255),

Estratégias de resistência, portanto, implicam hoje apostar nas diferenças. Fazer brotar diferenças na sociedade como brotam cogumelos no campo depois de uma chuva. Singularizar. Dissensos, em lugar de consensos manipulados.

Um movimento que crie teias de conhecimentos, que enrede interlocutores dispostos a transpor a educação maior, a partir de experimentos singulares, como o cinema na sala de aula e a produção de bio:grafias - propostos nesta pesquisa - por entendê-los como importantes elementos para a compreensão do cotidiano e as inquietações que nele e dele se fazem, como pontua Amorim (2005, p. 122-123),

[...] apostar que as singularidades podem ser mantidas é aquilo que mais podemos fluidificar e colocar em relação dentro das redes de poder que insistem em gerar a unidade, reduzir a multiplicidade aos princípios transcendentes, estabelecer passagens justas, iguais e comuns por entre experiências e trabalhos de formação e insistir em uma configuração/desfiguração nos opostos, movimentos dialeticamente, teorias e práticas, ensino e pesquisa, forma e conteúdo etc [...]

[...]que tenhamos, intensificadamente, currículos como espaços de encontros das diferenças, de desdobramentos em um comum-múltiplo, divergente, desfigurante.

Que possamos investir em práticas pedagógicas como espaços de produção das diferenças e de ampliação do sentido de cidadania para além dos currículos oficiais, mesmo compreendendo o quão difícil seja essa construção, como nos lembra Pontuschka (2005, p. 112),

A construção da cidadania como grande meta é extremamente difícil de ser realizada, pois na escola pública temos uma população numerosa, heterogênea do ponto de vista escolar e sociocultural - diferenças de idades, de valores, de hábitos, de origem sociais e culturais, em que os preconceitos e as ideologias somente são superados com muito trabalho por parte do conjunto dos professores. 
Porém, a construção da cidadania, entre outras possibilidades, pode ser percebida pela vivência e a ação daqueles que se fazem diferentes, se tornam corpos estranhos, em práticas cotidianas menores - suas trajetórias e bio:grafias são estratégias que desestabilizam as normas e fazem avançar as reflexões e criam novas possibilidades de viver a alteridade, na diferença, e isso acontece em todo o momento no cotidiano escolar (PROENÇA, 2009).

Tal investimento, assim como afirmam Reigota e Prado (2008), é ousar criativamente ao se valer das bio:grafias que muito têm a dizer sobre os/as alunos/as, o cotidiano da e na escola e os grupos nos quais estão inseridos socialmente, criando-se “possibilidades pedagógicas, políticas e de produção de conhecimentos e sentidos sobre a sociedade em que os sujeitos vivem e atuam" (REIGOTA; PRADO, 2009, p. 124).

Possibilitar a criação de bio:grafia pelas/os alunas/os da rede pública estadual, implica num importante fazer político, com pertinência pedagógica, que pode, apontar novos referenciais teóricos que extrapolem e incitem desconstruções de paradigmas engessados pela educação maior. É privilegiar outras práticas pedagógicas ao estilo dos rizomas e que dialogam com aquilo que Foucault (2007b) chamou de cuidado de si - um investimento na formação ética e estética de si.

\section{O cinema na sala de aula: ultrapassando a mera ilustração e tensionando questões da sexualidade}

Quando não se disse tudo sobre um determinado tema, fica-se com a possibilidade de imaginar o que não foi dito. A outra alternativa é apresentar ao público uma conclusão final que não exija nenhum esforço; não é disso, porém, que ele necessita. Que significado ela poderá ter para o espectador que não compartilhou com o autor a angústia e a alegria de fazer nascer uma imagem? (TARKOVSKIAEI, 1998, p. 18)

O cinema, com um grande número de produções fora do circuito comercial, vem apresentando inúmeras contribuições que possibilitam a efetivação da educação menor 
(GALLO, 2006) no cotidiano escolar, fazendo avançar questões, além das representações que se tem num determinado grupo ou sociedade.

Produções como Transamérica, de Duncam Tucker (EUA, 2005), The Bubble, de Eytan Fox (Israel, 2006), Madame Satã (Brasil, 2002) e O céu de Suely (Brasil, 2006) de Karim Aïnouz, Daens, um grito de justiça, de Stijn Coninx (Bélgica, França, Holanda, 1993), Milk - a voz da igualdade, de Gus Van Sant (EUA, 2008), Teus olhos meus, de Caio Sóh (Brasil, 2011), Hoje eu quero voltar sozinho, de Daniel Ribeiro (Brasil, 2014), entre outros tantos, conseguem trazer à cena, através de recortes de histórias mais ou menos complexas, fragmentadas e à deriva, temas polêmicos, controversos e por isso mesmo, significativos em apresentar a realidade de tantos/as personagens que têem um cotidiano marcado por representações de sua etnia, religião, cultura, política e existencial.

Medeiros (2009, p. 2), afirma:

O cinema e a linguagem imagética, numa sociedade técnica são, cada vez mais, elementos de ligação entre educadores e seus educandos, entre o conhecimento e a vida. Em razão da proximidade que as imagens estabelecem com o público, e pelo fato de satisfazerem à necessidade humana de se expressar, de se ver e de interagir, tornam-se hegemônicas em nossa cultura e fundamentais para a compreensão de nossa realidade contemporânea.

Reigota (1999, p. 44) contribui com a reflexão de como filmes que não estão no circuito comercial, trazem importantes elementos para pensar questões de mundo, da realidade e suas interfaces,

Atualmente, nenhum festival internacional de cinema que se preze deixa de lado filmes produzidos no Irã, na China e nos ex-países comunistas, já que os mesmos têm enriquecido a narrativa cinematográfica de forma geral e trazido à tona questões políticas e existenciais pouco abordadas pelo cinema comercial dos países que detêm o monopólio de difusão comercial.

Para Duarte e Alegria (2008, p. 74), “o contato com bons filmes altera o modo de ver e contribui para o desenvolvimento da capacidade de julgamento estético de obras cinematográficas e, por extensão, da produção audiovisual em geral”, e mais adiante 
afirmam, "as mostras e festivais de cinemas, tendem a "quebrar" a lógica do gosto constituída pelo acesso fácil, precoce e permanente a filmes de mesmo padrão estético e narrativo" (p. 75).

Assim, não há dúvidas que a utilização do cinema como aporte pedagógico na escola se torna fundamental, desde que tomados alguns cuidados, ou seja, que um filme não seja apenas utilizado para ilustrar um tema, mas de fato seja o gerador de uma reflexão maior, como afirma Pontuschka (2005, p. 134), ao tratar do ensino de geografia na escola, "a utilização de diferentes linguagens na geografia (obras literárias, cinema, vídeos, fotografias) pode auxiliar na compreensão e crítica da produção do espaço, se o seu uso como mera ilustração for superado" e, isso para todas as áreas do conhecimento, como fonte importante para a compreensão histórica, política, social, ideológica, científica, artística e estética das sociedades.

Medeiros (2009, p. 3), reflete sobre a importância do cinema na contemporaneidade e na escola, "se as imagens midiáticas disseminam ideias, valores e comportamentos, elas devem e podem ser problematizadas nos tempos e espaços escolares, favorecendo o desenvolvimento das aprendizagens sobre a existência humana".

O cinema, agregado ao cotidiano escolar, passa a contribuir para a educação do olhar, possibilitando outras maneiras de ver o mundo, outros entendimentos, poesias daquilo que nossos olhos se deparam no cotidiano, como propõe Amorim (2005, p. 122), ao fazer uso de photo grafias, "imagens como recursos de construção de nossas experiências cotidianas e de nosso imaginário".

O relato a seguir narra uma experiência vivenciada no/do/com o cotidiano escolar, justifica tais afirmações e quiçá oferece outras possibilidades das/dos alunas/os olharem para temas contemporâneos, como as homossexualidades, sem os véus e/ou máculas impostos socialmente e veiculados nos livros didáticos e meios midiáticos. 


\section{Experiência ou acontecimento? Currículo oculto enquanto máquina de guerra no cotidiano escolar}

Em 2009, trabalhando a disciplina de Geografia com uma turma de terceiro ano do ensino médio, o tema luta por emancipação de minorias étnicas na Europa e estendendo para outras minorias, inclusive aquelas percebidas no cotidiano das/os alunas/os; um dos estudantes relatou sobre um filme que havia visto - naquele momento ele trabalhava numa locadora de filmes - e que achava muito propício em relação ao tema que estávamos envolvidos.

O filme em questão era Transamérica (2005), um recorte da vida de uma transexual estadunidense - Bree Osbourne (Felicity Huffman) -, que prestes a passar pela cirurgia corretiva, recebe a notícia da existência de um filho adolescente, fruto de sua única experiência heterossexual, que muda os rumos de sua trajetória. Sua terapeuta cancela a cirurgia, pois a novidade instaura um conflito para a personagem: quem é, de fato, Bree Osbourne? Primeiro, ela deve buscar resolver, não sem mais conflitos, essa nova realidade, para constituir, de vez, sua identidade. Assim, sem muitas escolhas, Bree segue ao encontro do filho e sem revelar sua confusa identidade, viaja com ele, cruzando os Estados Unidos, num estilo de road movie - filme de estrada - ao qual, Louro (2004, p. 12-13), ressalta, 
Por conhecer o filme e a percepção de que poderia contribuir com um avanço e possibilitar novos olhares, realizamos uma sessão de cinema na escola. Num clima de desestabilização - era esperado que durante a projeção os meninos fizessem muitas piadas, que outros reclamassem do tema abordado ou de algumas cenas e, até mesmo, que alguns fariam queixa aos pais e esses poderiam procurar a direção da escola para reclamar de tal ação, alegando que estava desviando daquilo que era próprio da disciplina e que regem os documentos oficiais. Afinal, tal proposta nascera daquilo que se pode nomear educação menor, uma prática do cotidiano que extrapola a educação maior.

Talvez por esse enfrentamento, e porque estava evidente a necessidade de se discutir a temática, constataram-se algumas questões surpreendentes: os/as alunos/as passaram a se abrir para as questões de como as pessoas se tornam aquilo que são, procurando compreender as singularidades da personagem e, consequentemente, de outras pessoas, inclusive de seu círculo de convívio. Muitas questões surgiram, dúvidas em relação ao sexo, à sexualidade a aos gêneros. Estava instaurada a inquietação na sala de aula. Ou seja, o filme rendeu um bom debate e gerou outras reflexões a respeito de identidades de gênero e sexual, diversidade, homofobia e a luta por emancipação política das minorias, que tende, nos últimos anos, a aumentar significativamente, sua visibilidade, a notar pelo número de participantes das paradas gays, na cidade de São Paulo, ou mesmo em Sorocaba.

A conversa perpassou questões sobre a personagem Bree e seu filho: sua vida que se restringia a trabalhar para dar conta das inúmeras cirurgias que julgava necessárias para se tornar uma mulher por completo pode ser considerada legítima? Como a personagem se sentia em relação a si mesma e aos outros/as? A notícia de um filho, até então desconhecido, provocou mudanças na personagem? De que tipo? O encontro com o filho se deu de forma tranquila ou desestabilizou um ou outro, ou ambos os personagens? Como Bree tenta resolver o problema, filho? O que no filme provocou-lhes mais incômodo?

Podem-se levantar algumas características da heteronormatividade, relacionandoa com o comportamento de Bree, que quer fazer parte da sociedade, incluindo-se, mesmo que seja a partir de um “desde que” - a hipótese repressiva (FOUCAULT, 2007a) e, busca a melhor maneira de vestir-se, expressar-se, comportar-se como uma mulher. 
Para ela, não importa as reflexões discutidas sobre as questões das minorias, se há ou não grupos de luta por direitos e emancipação ou de que forma têm-se contestado o poder heteronormativo da sociedade, mas sim, tornar-se parte dessa sociedade, sem levantar quaisquer suspeitas sobre a sua condição ambígua, e isso não deixa de ser uma possibilidade tão legítima como qualquer outra.

A conversa abordou, ainda, sobre a posição da família de Bree antes e, depois de saberem que ela tinha um filho já adolescente e questionando como na atualidade, as famílias reagem ao saberem que seus/suas filhos/as estão assumindo uma sexualidade não heterossexual/convencional.

Como conclusão, foi solicitado que cada um/a produzisse um texto apontando suas principais reflexões, aquilo que mais Ihes chamou a atenção ou o que mais lhes incomodou.

O resultado dessa prática escolar foi uma experiência singular, restrita a sala de aula, "longe das determinações legais, distantes das proposituras de políticas nacionais; mas que fazem toda a diferença para as comunidades nas quais são desenvolvidas" (GALLO, 2006, p. 91), ou seja, as/os alunas/os, juntamente com o professor, alcançaram um grau de reflexão, aprendizagem e de compreensão da dimensão humana que não está em nenhuma das situações de aprendizagem da dita educação maior, aqui representada pela Proposta Curricular da Secretaria de Educação do Estado de São Paulo, ou outros documentos oficiais da educação estadual ou nacional.

Mesmo não apresentando julgamento de qualidade e estética da obra, visto que para tal, exigem-se conhecimentos específicos e na maioria das vezes, como apontam Duarte e Alegria (2008, p. 75), os/as alunos/as estão acostumados a verem sempre o mesmo tipo de filme, "o padrão do cinema hollywoodiano, hegemônico hoje no mercado mundial", outros olhares foram despertados pela história não linear da personagem Bree, provocando questionamentos e desestabilizando certezas, numa construção do novo, do diferente que é possível e que, inclusive, pode estar, e está certamente, acontecendo em nosso cotidiano escolar.

O que se segue, são fragmentos de textos dos/as alunos/as, bio:grafias, como produção singulares de suas reflexões a partir do filme Transamérica (2005) e dos debates 
realizados. Fica claro, em algumas escritas, tanto aquilo que vivenciam em seu cotidiano dentro e fora da escola, bem como desconstruções que empreenderam no decorrer do trabalho realizado.

As transcrições dos textos se encontram como nos originais.

Nos tempos de hoje, vivemos numa sociedade muito preconceituosa, onde costumes religiosos influênciam muito. Antigamente homossexuais, transformistas e etc... eram vistos como uma aberração humana e se perguntavam: o que leva uma pessoa a virar o que é?

Há várias respostas para essa pergunta, a mais aceita pelas pessoas é uma tendência sexual que ela trás bem antes de virar um homossexual ou outra coisa qualquer $[\ldots]$

Com o desenvolvimento global esse preconceito vem caindo gradativamente, onde homossexuais interagem normalmente com as pessoas. Passeatas com trios elétricos todo ano acontecem em vários lugares do Brasil e do mundo, a chamada Parada Gay, onde os homossexuais querem mostrar sua forma e que são muitos unidos entre si, para acabar com esse preconceito. R.S.R.

O filme mostra que ninguém é igual a ninguém, que cada pessoa tem a sua experiência de vida, que cada um faz o que quer com o seu corpo, e que quem está de fora é muito mais fácil criticar, dar opiniões e muitas vezes ofendem as pessoas [...]

Cada pessoa tem o livre arbítrio para decidir o que vai falar, comer, vestir, se vai modificar ou não seu corpo. Uma coisa errada do filme é o filho dela(e) que não aceitou. Só que no final dá tudo certo. Com isso, vemos que não devemos pré-julgar uma pessoa só pelo que ela aparenta ser, mas sim conhece-la melhor.[...] S.G.S.

Antes de ver o filme imaginava que se tratava apenas em contar a opção de vida de alguém. Mas depois de assisti-lo fiquei impressionada com a história, não sei se foi baseada em fatos reais, mas sei que muito mais que imaginamos isso acontece no mundo real. Vivemos rodeados de pessoas e nem nos preocupamos em quais são suas reais vontades ou verdades $[. .$.

A discriminação de pessoas que escolhem um modo de vida "diferente" é constante, mas quem sabe o que eles(as) sentem (e no filme isso fica bem claro já que a única certeza que Bree tem na vida é de que ela quer fazer a cirurgia). Em muitas vezes pessoas como Toby não "escolhem" essa opção, ela é praticamente imposta, já que uma criança não sabe se "isso" que fazem com ela é certo ou errado, e passam a conhecer uma só verdade, que logo se transforma em uma vontade.

E não se trata só de opção sexual, mas de todas outras opções que devem ser respeitadas e que podem ser discriminadas de várias formas, 
seja pela opção sexual, modo de vida e até nossa personalidade é discriminada, em tudo somos questionados. Quem nos discrimina nada mais quer se não nos tornar iguais a eles, por acreditarem que só eles sabem o que é a verdade. I.F.M.

O filme ajuda a compreendermos o modo de vida dos transexuais.

O que incomodou e não precisaria nem do filme é o preconceito, e isso não vai mudar, pois as pessoas tem a ideia de que todos temos de ser heterossexuais, isso está imposto pela sociedade, que ainda tem um pensamento (na maioria das vezes) crítico em relação aos homossexuais, e muitos outros tipos de pessoas como os protestantes, os negros, mulheres, etc.

Algo que me chamou bastante atenção é a força de vontade da Bri, mesmo a mãe dela não a aceitando como uma transexual [...] J.M.

O filme "Transamérica" não acrescentou nada em relação a que eu já pensava sobre o assunto, cada um é dono de si e responsável pela suas atitudes então faz o que quer.

É claro que todos nós podemos viver em sociedade sem preconceitos, nos respeitando, mesmo com as nossas indiferenças, opiniões, costumes, gostos, crenças, o jeito de ser e de pensar. Com certeza não é isso que acontece na sociedade em que vivemos, onde tratamos na maioria das vezes, como "aberrações da natureza", o que acaba sendo uma ignorância coletiva pelo fato que o número de pessoas que tem companheiros do mesmo sexo e pessoas que querem fazer a troca de sexo definitivamente só vem crescendo [...] S.A.S.

O filme me passou dois pontos de vista sobre o que acontece. O ponto ruim do filme que não pude concordar muito foi o fato de os próprios pais da personagem não aceitar sua mudança, eu creio que isso o que eles fazem não é certo, porque pais de verdade aceita os seus filhos independentemente das suas escolhas que eles façam.

Um dos pontos que achei importante foi a confiança e a coragem que o personagem nos passa, a coragem de enfrentar tudo e todos para que possa alcançar seus objetivos e suas decisões[..] D.A.A.S.

[...] Apesar de eu não ter nada contra, temos toda uma polêmica sobre esse assunto na sociedade, a não aceitação de pessoas que vivem de forma diferente é julgada até mesmo pela religião, o preconceito é muito grande, essas pessoas são normais, são como qualquer um deste mundo, mas são tratados como bicho de sete cabeças, pessoas sem sentimentos, o que na verdade não são. 
Eles tem personalidades diferentes, cada um tem seu jeito e forma de viver, cabe a cada um de nós não julgar tais pessoas antes de ao menos conhecê-la. T.P.A.

O mundo é coberto com novas culturas, costumes, a cada dia há novas "tribos", gêneros de pessoas, religiões, cada um com seu estilo de vida, com o certo a fazer a cada um. O que é certo pra mim, pode ser errado para outro, o que é normal pra mim, é anormal pra outro.

Cada um tem a liberdade de pensar o que quer, ir aonde quer, ser o que quiser, mesmo não sendo aceito por outros na sociedade tradicional [...] Particularmente não sou a favor de outra opção sexual, que não seja a relação heterossexual, mas mesmo não concordando, tenho o dever de aceitar e respeitar os que assim escolhem viver [...] P.A.B.

[...] Confesso que possuo um pouco de preconceito em relação ao homosexualismo. Eu os respeito por suas decisões, não faço piadas de mal gosto, mas não gostaria que no futuro meu filho se tornasse homosexual.

Isto não significa que iria virar as costas para ele, eu iria apoiá-lo para fazer com que ele fosse procurar e ser feliz como ele quisesse [...] J.A.A.

Em todos os fragmentos, percebem-se traços de múltiplas identidades, narrativas que contam da vida, de suas representações sociais e das experiências que os/as alunos/as vivenciam em casa, na sociedade, nos grupos que participam e também na escola. Suas vidas, histórias, crenças, valores, instigam a querer saber mais sobre cada um/a, pois como afirma Reigota (2003, p.9), "um tipo de conhecimento específico pode fazer (e faz) a diferenças entre os sujeitos, da mesma forma com que os distingue a interpretação e a ação que têm da e na história", apontando novos rumos para a efetivação de uma educação que realmente esteja pautada na democracia e na valorização das singularidades experimentadas por todos/as os/as envolvidos/as no processo pedagógico.

A prática pedagógica exposta acima, vivenciada no e com o cotidiano escolar, no período curto de no máximo duas semanas, possibilitou um avanço para a percepção da sexualidade enquanto construto histórico, que se compõe à medida que todo um conjunto de normas vai se estabelecendo, de acordo com os interesses sociais de um 
determinado grupo, bem de acordo com aquilo que Foucault afirma em seus estudos da sexualidade e assim compreendido por Dinis e Lima (2009, p. 50) "a escola parece ter o papel de ensinar como cada aluno (a) deve conduzir a sua sexualidade, segundo um padrão social estabelecido e de acordo com os saberes considerados portadores de uma verdade sobre a saúde e sua relação com o sexo (ato sexual)".

Ainda de acordo com esses autores (DINIS; LIMA, 2009, p. 51), a escola e a sociedade investem na formação heterossexual de todos os sujeitos, como via de norma, provocando preconceitos contra aqueles que não apresentam as características normativas, fazendo das homossexualidades, algo depreciativo.

Na escola - assim como na sociedade em geral - não são apontadas possibilidades ou alternativas para a construção da sexualidade. A homossexualidade é vista como o 'outro', como o desvio da norma, como uma dolorosa experiência de sexualidade que não aponta positividades. Com essa visão, educa-se a criança para a 'normalidade', evitando que ela tenha contato com as diferenças.

Desta forma, a presente pesquisa vem subverter o que se convencionou chamar de normal ou normalidade, no campo das sexualidades, ao tensionar sobre o que o pode ou não ser dito dentro e fora dos muros da escola. E, muito mais, ao inverter a lógica da educação tradicional, dando significado às emergências que surgem no cotidiano escolar - a educação menor - ocasionou acontecimentos, criação de novos saberes, novos pensamentos, novos posicionamentos, novas perspectivas e novos olhares sobre os corpos, gêneros e suas vivências sexuais. 


\section{Referências}

AMORIM, Antonio Carlos Rodrigues de. Photo grafias, escritascotidiano e currículos deformação. In: FERRAÇO, Carlos Eduardo (Org.). Cotidiano escolar, formação de professores(as) e currículo. São Paulo: Cortez, 2005. (Série cultura, memória e currículo; v. 6)

DAENS, UM GRITO DE JUSTIÇA. Dir. Stijn Coninx. Favourite Films, Films Dérives. Bélgica, França, Holanda, 1993. 1DVD.

DELEUZE, Gilles; GUATTARI, Félix. Mil platôs: capitalismo e esquizofrenia. Tradução de Aurélio Guerra Neto e Celia Pinto Costa. São Paulo: ED. 34, 1995, vol. 1. (Coleção TRANS) $6^{\text {a }}$ Reimpressão - 2009.

DINIS, Nilson Fernandes; LIMA, Francis Madlener. Pra que time ele joga?: a produção da identidade homossexual em um vídeo educativo. Arquivos Brasileiros de Psicologia. Rio de Janeiro: UFRJ, v. 61, n. 1, 2009. p. 49-59. Disponível em: <

http://146.164.3.26/seer/lab19/ojs2/index.php/ojs2/article/view/365/290>. Acesso em 27 jul. 2010.

DUARTE, Rosália; ALEGRIA, João. Formação estética audiovisual: um outro olhar para o cinema a partir da educação. Educação \& Realidade. Porto Alegre: UFRS, v. 33. n. 1, p. 5979, Jan./Jun. 2008.

FINI, Maria Inês (Coord.). Proposta curricular do Estado de São Paulo: Geografia. São Paulo: SEE, 2008.

FISCHER, Rosa Maria Bueno. Docência, cinema e televisão: questões sobre formação ética e estética. Revista Brasileira de Educação. Rio de Janeiro: Autores Associados, v. 14, n. 40, jan./abr. 2009. p. 93-102.

FOUCAULT, Michael. História da sexualidade I: a vontade de saber. Tradução de Maria Thereza da Costa Albuquerque e J. A. Guilhon Albuquerque. 18 ed. Rio de Janeiro: Edições Graal, $2007 a$.

FOUCAULT, Michael. História da Sexualidade III: o cuidado de si. Tradução de Maria Thereza da Costa Albuquerque; revisão técnica de José Augusto Guilhon Albuquerque. 9 ed. Rio de Janeiro: Edições Graal, 2007b.

FREIRE. Paulo. Pedagogia da autonomia: saberes necessários à prática educativa. 16 ed. São Paulo: Paz e Terra, 2000.

GALLO, Sílvio. Transversalidade e educação: pensando uma educação não-disciplinar. In: ALVES, Nilda; GARCIA, Regina Leite. O sentido da escola. 3. ed. Rio de Janeiro: DP\&A, 2002. p. 17-41. 
GALLO, Sílvio. Deleuze \& a educação. Belo Horizonte: Autêntica, 2003.

GALLO, Sílvio. O Ensino Fundamental: formação e transformação. Quaestio: Revista de Estudos de Educação. Sorocaba, SP, v. 8, n. 2, p. 89-104, nov. 2006.

GALLO, Sílvio. Pedagogia libertária: anarquistas, anarquismos e educação. São Paulo: Imaginário: Editora da Universidade Federal do Amazonas, 2007.

GUATTARI, Félix. As três ecologias. Tradução: Maria Cristina F. Bittencourt. 6 ed. Campinas, SP: Papirus, 1997.

HOJE eu quero voltar sozinho. Dir. Daniel Ribeiro. Brasil, 2014. 1DVD.

LOURO, Guacira Lopes (Org.). O corpo educado: pedagogias da sexualidade. Tradução dos artigos Tomaz Tadeu da Silva. Belo Horizonte: Autêntica, 1999.

LOURO, Guacira Lopes. Um corpo estranho: ensaios sobre a sexualidade e teoria queer. Belo Horizonte: Autêntica, 2004.

LOURO, Guacira Lopes. Gênero e sexualidade: pedagogias contemporâneas. ProPosições. Campinas, SP, v. 19, n. 2 (56), p. 17-23, maio/ago. 2008.

MADAME Satã. Dir. Karim Aïnouz. Imagem Filmes. Brasil, 2002. 1DVD.

MEDEIROS, Sérgio Augusto Leal de. Cinema na escola com Walter Benjamin. In: Reunião da ANPED: Sociedade, cultura e educação: novas regulações? 32. 2009, Caxambú, MG.

Anais da $32^{a}$ Reunião Anual da Anped. Disponível em:

<http://www.anped.org.br/reunioes/32ra/arquivos/trabalhos/GT16-5653--Int.pdf>. Acesso em 10 abr. 2010.

MILK, a voz da igualdade. Dir. Gus Van Sant. Focus Features, Axon Films, Groundswell Productions, Jinks/Cohen Company. EUA, 2008.1DVD.

O CÉU de Suely. Dir. Karim Aïnouz. Videofilmes, Celluloid Dreams e Shotgun Pictures. Brasil, 2006. 1DVD.

PONTUSCHKA, Nídia Nacib. Geografia, representações sociais e escola pública. Terra Livre, São Paulo, SP, n. 15. p. 125-154, 2000.

PONTUSCHKA, Nídia Nacib. A geografia: pesquisa e ensino. CARLOS, Ana Fani Alessandri (Org.). Novos caminhos da geografia. 5 ed. São Paulo: Contexto, 2005. (Caminhos da geografia). p. 111-142.

PROENÇA, Eder Rodrigues. Cartografia dos corpos estranhos: narrativas ficcionais das homossexualidades no cotidiano escolar. 2009. 159f. Dissertação (Mestrado em Educação) - Universidade de Sorocaba, Sorocaba, SP. 
RAGO, Margareth; VEIGA-NETO, Alfredo (Orgs.). Para uma vida não-fascista. Belo Horizonte: Autêntica Editora, 2009. (Coleção Estudos Foucaultianos).

REIGOTA, Marcos. Ecologistas. Santa Cruz do Sul: EDUNISC, 1999.

REIGOTA, Marcos; POSSAS, Raquel; RIBEIRO, Adalberto (Orgs.). Trajetórias e narrativas através da educação ambiental. Rio de Janeiro: DP\&A, 2003.

REIGOTA, Marcos; PADRO, Bárbara Heliodora Soares do (Orgs.). Educação ambiental: utopia e práxis. São Paulo: Cortez, 2008. (Coleção cultura, memória e currículo; v. 8)

TARKOVSKIAEI, Andrei Arsensevich. Esculpir o tempo. Tradução Jefferson Luiz Camargo. 2 ed. São Paulo: Martins Fontes, 1998.

TEUS olhos meus. Dir. Caio Sóh. Brasil, 2011. 1DVD.

THE BUBBLE. Dir. Eytan Fox. Imovision. Israel, 2006. 1DVD.

TRANSAMÉRICA, Dir. Duncan Tucker. Focus Filmes. EUA, 2005. 1DVD.

Recebido em: 10/04/2015 Aprovado em: 14/07/2015

Universidade do Estado de Santa Catarina - UDESC

Programa de Pós-Graduação em Educação - PPGE

Revista Linhas

Volume 16 - Número 32 - Ano 2015

revistalinhas@gmail.com 